\title{
Parenting Styles and Suicidal Ideation in Pakistani Adolescents
}

Naveed Sultan ${ }^{1}$, Zainab Javed ${ }^{2}$

\begin{abstract}
Suicide is described as death caused by self-directed injurious behavior with any intent to die as a result of the behavior. Adolescence is a period of marked risk for suicide. This study was carried out to find out the relationship of parenting style and suicidal ideation of adolescents. A sample of $(\mathrm{N}=200)$ with age range of 13 to 19 years from different schools of Khyber Pakhtun Khwa, Pakistan was selected. Two instruments were used in study: Parental Authority Questionnaire (PAQ), and Suicidal Risk Scale (SRS). Pearson partial correlation was applied to analyze the data. The findings shows permissive mother parenting style is significantly positively correlated with authoritarian mother parenting, permissive father parenting, authoritarian father parenting, and suicidal ideation. Whereas, authoritarian mother parenting style significantly positively correlated with permissive father parenting, authoritarian father parenting, and suicidal ideation. Meanwhile authoritative/flexible mother parenting style is significantly negatively correlated with permissive father parenting, authoritarian father parenting, and suicidal ideation.
\end{abstract}

Key Words: Parenting Style; Permissive Parenting Style; Authoritative Parenting Style; Authoritarian Parenting Style; Suicidal Ideation; Adolescents

Received: 26 May 2020; Revised Received: 29 October 2020; Accepted: 01 December 2020

${ }^{1}$ M. Phil Scholar, Riphah Institute of Clinical \& Professional Psychology, Riphah International University, Lahore Campus.

${ }^{2}$ Visiting Lecturer, Riphah Institute of Clinical \& Professional Psychology, Riphah International University, Lahore Campus.

\section{Corresponding Author Email:}

naveedsultanjarral@gmail.com

\section{INTRODUCTION}

Arria et al. (2009) described suicide is a third leading cause of youngest death; many individuals with youth are reported having suicidal thoughts and suicidal attempt as well. While suicide is the fourth major cause of death in young children with the age 12 years (Hoyert et al., 2006). Suicide becomes an acute global health problem, the most highlighted area where the suicidal rate is reported very high are Asia and South Asia. This is also an alarming situation that Asia is a more crowded place than any other. China and India are the most populated countries with the greater part of World's suicide rate (Hendin et al., 2008). Adolescence is a period of marked risk for suicide (Kann et al., 2014). If we take a look on the US, the rate of death among young adults and youth from 10 to 24 years have a high risk of suicidal attempt and is the third largest cause of death. According to researchers, 4559 cases are reported in 2004 in the US (Lubell et al., 2007).

Reynolds (1988) characterized suicidal ideation as "the area of contemplations and thoughts regarding passing, suicide, and genuine self-harmful conduct, including musings identified with the arranging, direct, and result of self-destructive conduct." selfdestructive ideation is characterized as pondering, considering, or arranging suicide

This article is distributed under the terms of the Creative Commons Attribution Non Commercial 4.0 License (http://www.creativecommons.org/licenses/by-nc/4.0/) which permits non-Commercial use, reproduction and distribution of the work without further permission provided the original work is attributed as specified. 
(Logan et al., 2011).The three important factors in suicide are; dynamic selfdestructive want, explicit designs for suicide

The accepted way of thinking that detached suicidal ideation presents fewer hazards for suicide than dynamic self-destructive ideation is saturated with the legend of mental practice. "Aloof self-destructive ideation" seems on many occasions in mental records, articles, writings, rules, and clinical talk. At the point when a patient reports latent suicide ideation, the clinician may take advantage of it as a marker of generally safe of suicide. The clinician may feel assuaged and not play out an exhaustive suicide chance evaluation whether suicide ideation is dynamic or latent; the objective is the equivalent ending one's life. Suicidal ideation, for example, the desire to kick the bucket during rest, to be murdered in a mishap, or to create terminal malignant growth, may appear to be generally innocuous, however it very well may be similarly as unfavorable as considerations of hanging oneself. Albeit uninvolved suicidal ideation may permit time for intercessions, latent ideation can all of a sudden turn dynamic (Simon, 2008).

Parenting is the process of assisting and encouraging the physical, emotional, social and mental growth of a child from birth to adulthood. It is a way through which relationship between parent and child is reflected. Parenting is an intricate process that involves much more than a mother or father providing food, safety and support for the child. It is an intricate activity, which encompasses various explicit attitudes and behaviors that work independently and collectively in child outcomes and builds an emotional connection where the behavior of parents is communicated (Darling \& Steinberg, 1993; Darling, 1999). Therefore, parenting as the style of raising a child refers to an entitlement or responsibility of mother and detached self-destructive want (Beck et al., 1979).

and father, together or separately to groom the child for society and culture (Veenes, 1973). Consequently, every parent has a unique attitude, behavior, belief, values and family culture and all these standards differ from parent to parent (Bibi et al., 2013). Parenting style is a term referred to behaviors and strategies used by parents to regulate and socialize their children (Cole et al., 2005). Parenting style as a constellation of attitudes towards the child that are communicated to the child and that, taken together, create an emotional climate in which the parent's behaviors are expressed (Darling \& Steinberg, 1993).

Adolescence is a period of marked risk for suicide (Kann et al., 2014). For youth between the ages of 10 and 24 years, suicide is the third leading cause of death, significantly superseding the rate for adults aged 35 to 54 years. Males are more likely to die as a result of suicide: the male-to-female ratio of death by suicide is four to one in the U.S. (Kann et al., 2014; Kochanek et al., 2004). Suicide attempt is defined as a nonfatal self-directed potentially injurious behavior with any intent to die as a result of the behavior; a suicide 54attempt may or may not result in injury (Logan et al, 2011). In almost all regions of the world, nonlethal suicide attempts are more common in females. Males are more likely to use more lethal means than females, partially accounting for the different pattern for suicide deaths and attempts (Kann et al., 2014; Lai \& McBride-Chang, 2001).

A few researches have focused on this age group in Pakistan regarding the prevention of suicide and decrease the rate of suicide in specific culture, region and gender. In past, very few researches were conducted in eastern countries like Pakistan, India, 
China etc. This study will be covering the literature gap on parenting styles and suicidal ideation in Pakistani Adolescents. Very few researches conducted on this topic but most of them covers gender differences in suicide

\section{METHOD}

\section{Sampling}

The cross sectional and survey research design was used for data analysis. Adolescent's age range was 14 to 19 years and selected through the purposive sampling.

\section{Measures}

Reliability analysis was examined through alpha coefficient to determine the internal consistency of each selected variable. Reliability of Parental Authority Questionnaire (PAQ) is Mother Authoritarian $=0.83$, Mother Authoritative = 0.83, Mother Permissive $=0.74, \&$ Father Authoritarian $=0.86$, Father Authoritative $=$ 0.86, Father Permissive $=0.75$ (Buri, 1991). This suggests that PAQ is incredibly reliable.

\section{Data Analysis}

Different analyses techniques are performed to study the relationship in parenting style, and suicidal ideation in adolescent. The Statistical Package for the Social Sciences software version 22 was used to analyze data. Descriptive statistics were calculated to assess means, standard deviations and prevention program (Kann et al., 2014; Khokher \& Khan, 2005). There are also very few researches are available on parenting styles and adolescents suicidal relationship.

Adolescents were selected from different high and higher secondary schools from Khyber PakhtunKhwa province.

Suicidal Risk Scale is 13 items scale used for assessing the adolescent suicidal ideation. It was developed by Tse and Bagley (2002). Respondent choose the option on a 4-point Likert scale. The scale is ranging from strongly agree to strongly disagree. High score indicate that there were more negativity among respondent toward suicide and there is high level of suicidal Ideation. In previous study by Tse and Bagley (2002), it was showed that the scale has reliability and validation in suitable range.

frequencies of the variables. Pearson product moment correlation was computed to find relationship in parenting style, and suicidal ideation in adolescents. Hierarchical regression analysis was used to find the predictor relationship with the outcome. 


\section{RESULTS}

Table 1

Reliability Analysis and Descriptive Statistics of all Scales $(N=200)$

\begin{tabular}{lllllll}
\hline Variables & & & \multicolumn{2}{l}{ Range } \\
\cline { 6 - 7 } & $\boldsymbol{M}$ & $\boldsymbol{S D}$ & $\boldsymbol{A}$ & Potential & Actual & Skew \\
\hline Permissive Mother & 30.87 & 6.42 & .69 & $10-50$ & $12-49$ & -.06 \\
Authoritarian Mother & 30.87 & 6.66 & .71 & $10-50$ & $11-48$ & .10 \\
Authoritative/flexible Mother & 29.28 & 6.91 & .62 & $10-50$ & $11-47$ & -.48 \\
Permissive Father & 29.73 & 6.81 & .68 & $10-50$ & $11-48$ & .15 \\
Authoritarian Father & 30.81 & 6.91 & .69 & $10-50$ & $11-47$ & -.11 \\
Authoritative/flexible Father & 28.19 & 7.11 & .73 & $10-50$ & $10-44$ & -.38 \\
Suicidal Ideation & 201.02 & 53.63 & .90 & $73-292$ & $108-226$ & .68 \\
\hline
\end{tabular}

The results show that Suicidal Ideation and Parenting Style scales for father (Authoritative/Flexible) and mother (Authoritarian) in the present research show the acceptable range of Cronbach's alpha. The acceptable range of Cronbach's alpha is
.70 to 90 . While, the values of Cronbach's alpha for permissive Mother, Authoritative/flexible (Mother), Permissive (Father) and authoritarian (Father) show the questionable range (.62 to .69) but can be used in present research.

\section{Table 2}

Correlation among all variables $(N=200)$

\begin{tabular}{|c|c|c|c|c|c|c|c|c|c|}
\hline Variables & 1 & 2 & 3 & 4 & 5 & 6 & 7 & 8 & 9 \\
\hline 1.permissive Mother & - & $.85 * *$ & $-49 * *$ & $.79 * *$ & $.83 * *$ & $.30 * *$ & $-.55 * *$ & $-.35 * *$ & $.51 * *$ \\
\hline 2. Authoritarian & & - & $-.48 * *$ & $.83 * *$ & $.82 * *$ & $-.23 * *$ & $-.51 * *$ & $-.30 * *$ & $.43 * *$ \\
\hline $\begin{array}{l}\text { 3. Authoritative/flexible } \\
\text { Mother }\end{array}$ & & & - & $-.47 * *$ & $-.48 * *$ & $.77 * *$ & $.63 * *$ & $.48 * *$ & $-.54 * *$ \\
\hline 4. Permissive Father & & & & - & $.93 * *$ & $-.54 * *$ & $-.62 * *$ & $-.35 * *$ & $.61 * *$ \\
\hline 5. Authoritarian Father & & & & & - & $-.49 * *$ & $-.63 * *$ & $-.37 * *$ & $.54 * *$ \\
\hline 6. Authoritative/flexible & & & & & & - & $.60 * *$ & $.46^{* *}$ & $-.61 * *$ \\
\hline Father & & & & & & & & & \\
\hline 7. Suicidal Ideation & & & & & & & & & - \\
\hline
\end{tabular}

This table shows that permissive mother parenting style is significantly positively correlated with authoritarian mother parenting, permissive father parenting, authoritarian father parenting and suicidal ideation. Meanwhile, authoritative/flexible mother parenting style is significantly negatively correlated with permissive father parenting, authoritarian father parenting, and suicidal ideation. Additionally, permissive father parenting style is significantly positively correlated with authoritarian father authoritarian father parenting, and suicidal ideation. Whereas, authoritarian mother parenting style is significantly positively correlated with permissive father parenting, parenting, and suicidal ideation. Whereas, authoritarian father parenting style is significantly positively correlated with suicidal ideation. Meanwhile, authoritative/flexible father parenting style is significantly negatively correlated with suicidal 
Table 3

Impact of Permissive Parenting (Mother) on Suicidal Ideation $(N=200)$

\begin{tabular}{lll}
\hline & \multicolumn{2}{l}{ Suicidal Ideation } \\
\cline { 2 - 3 } Predictors & B & 95\% CI \\
\hline Constant & $195.89^{* *}$ & {$[139.73,252.05]$} \\
Permissive Parenting (Mother) & $2.41^{* *}$ & {$[1.34,3.47]$} \\
$\mathrm{R}^{2}$ & .39 & \\
$\mathrm{~F}$ & $42.33^{* *}$ & \\
\hline
\end{tabular}

${ }^{* *} p<.01$; B for Unstandardized regression coefficient; CI for Confidence interval

The result of table 3 shows that model 1 explains that permissive parenting style (mother), contribute $39 \%$ of variance $\left(\mathrm{R}^{2}=\right.$
.39) in suicidal ideation. While, permissive parenting (mother) found significant predictor of suicidal ideation.

Table 4

Impact of Authoritarian Parenting (Mother) on Suicidal Ideation $(N=200)$

\begin{tabular}{lll}
\hline & \multicolumn{2}{l}{ Suicidal Ideation } \\
\cline { 2 - 3 } Predictors & B & 95\% CI \\
\hline Constant & $241.96^{* *}$ & {$[189.91,294.02]$} \\
Authoritarian Parenting (Mother) & $1.51^{* *}$ & {$[.49,2.52]$} \\
$\mathrm{R}^{2}$ & .36 & \\
$\mathrm{~F}$ & $36.67^{* *}$ & \\
\hline
\end{tabular}

${ }^{* *} p<.01$; B for Unstandardized regression coefficient; CI for Confidence interval

The result of table 4 shows that model 1 explains that authoritarian parenting style (mother) contribute $36 \%$ of variance $\left(\mathrm{R}^{2}=\right.$
.36) in suicidal ideation. While, authoritarian parenting (mother) significant predictor of suicidal ideation.

Table 5

Impact of Authoritative Parenting (Mother) on Suicidal Ideation $(N=200)$

\begin{tabular}{lll}
\hline \multirow{2}{*}{ Predictors } & \multicolumn{2}{l}{ Suicidal Ideation } \\
\cline { 2 - 3 } Constant & B & 95\% CI \\
Authoritative Parenting (Mother) & $335.45^{* *}$ & {$[306.39,364.49]$} \\
$\mathrm{R}^{2}$ & $-3.04^{* *}$ & {$[-4.29,-1.78]$} \\
$\mathrm{F}$ & .40 & \\
\hline
\end{tabular}

${ }^{* *} p<.01 ;{ }^{*} p<.05 ; \mathrm{B}$ for Unstandardized regression coefficient; CI for Confidence interval

The result of table 5 shows that model 1 explains that authoritative parenting style (mother) contribute $40 \%$ of variance $\left(\mathrm{R}^{2}=\right.$
.40) in suicidal ideation. While authoritative parenting (mother), found significant predictor of suicidal ideation in adolescents. 
Table 6

Impact of Permissive Parenting (Father) on Suicidal Ideation $(N=200)$

\begin{tabular}{lll}
\hline & \multicolumn{2}{l}{ Suicidal Ideation } \\
\cline { 2 - 3 } Predictors & B & 95\% CI \\
\hline Constant & $147.7 *^{* * *}$ & {$[91.04,204.37]$} \\
Permissive Parenting (Father) & $3.40^{* *}$ & {$[2.33,4.48]$} \\
$\mathrm{R}^{2}$ & .44 & \\
$\mathrm{~F}$ & $51.82^{* *}$ & \\
\hline
\end{tabular}

${ }^{* *} p<.01$; B for Unstandardized regression coefficient; CI for Confidence interval

The result of table 6 shows that model 1 in suicidal ideation. While, permissive explains that permissive parenting style parenting (father) found significant predictor (father), contribute $44 \%$ of variance $\left(\mathrm{R}^{2}=.44\right)$ of suicidal ideation

\section{Table 7}

Impact of Authoritarian Parenting (Father) on Suicidal Ideation $(N=200)$

\begin{tabular}{lll}
\hline & \multicolumn{2}{l}{ Suicidal Ideation } \\
\cline { 2 - 3 } Predictors & B & 95\% CI \\
\hline Constant & $194.2 *^{* * *}$ & {$[134.04,254.36]$} \\
Authoritarian Parenting (Mother) & $2.34^{* *}$ & {$[1.23,3.44]$} \\
$\mathrm{R}^{2}$ & .39 & \\
$\mathrm{~F}$ & $41.02^{* *}$ & \\
\hline
\end{tabular}

${ }^{* *} p<.01$; B for Unstandardized regression coefficient; CI for Confidence interval

The result of table 7 shows that model 1 in suicidal ideation. While, authoritarian explains that authoritarian parenting style parenting (father) found significant predictor (father), contribute $36 \%$ of variance $\left(\mathrm{R}^{2}=.39\right) \quad$ of suicidal ideation.

Table 8

Impact of Authoritative Parenting (Father) on Suicidal Ideation $(N=200)$

\begin{tabular}{lll}
\hline & \multicolumn{2}{l}{ Suicidal Ideation } \\
\cline { 2 - 3 } Predictors & B & 95\% CI \\
\hline Constant & $338.15^{* *}$ & {$[311.49,364.81]$} \\
Authoritative Parenting (Mother) & $-3.58^{* *}$ & {$[-4.59,-2.57]$} \\
$\mathrm{R}^{2}$ & .47 & \\
$\mathrm{~F}$ & $56.76^{* *}$ & \\
\hline
\end{tabular}

${ }^{* *} p<.01 ;{ }^{*} p<.05 ; \mathrm{B}$ for Unstandardized regression coefficient; CI for Confidence interval

The result of table 8 shows that model 1 in suicidal ideation. While, authoritative explains that authoritative parenting style parenting (father) was found significant (father) contribute $47 \%$ of variance $\left(\mathrm{R}^{2}=.47\right)$ predictor of suicidal ideation.

\section{DISCUSSION}

This study is the first to examine the level of parenting style and suicidal ideation in adolescents in KPK, to identify which parenting style strongly associated with 
suicidal ideation, and predictive of suicidal thoughts, because poor parenting style in adolescents faced many problem at home and schools/colleges. In current society parents are more worried about their children many of Results showed that permissive mother parenting style is significantly positively correlated with authoritarian mother parenting, permissive father parenting, authoritarian father parenting, and suicidal ideation. The current study have a similar results by Nunes and Mota (2016) who previously conducted research on parenting style and suicidal ideation in adolescence. The study showed relationship between different parenting styles; authoritative, authoritarian and permissive parenting style (Baumrind, 1991). Those who focus on the parenting study must know and concern with the negative effect that can be adopted by parents with character of authoritative parenting behaviors and its effects on the psychological health of child. Moreover, it is very important for the mental

\section{Conclusion}

Authoritative/flexible mother parenting style is significantly negatively correlated with permissive father parenting, authoritarian father parenting, and suicidal ideation. Additionally, permissive father parenting style is significantly positively correlated with authoritarian father parenting, and suicidal ideation. Whereas, authoritarian father parenting style is significantly positively correlated with suicidal ideation, meanwhile

\section{Limitations and Recommendations}

The sample was collected from schools of only one province of Pakistan, so one needs to be careful while generalizing the results of the study. In future it can be collected from other areas of Pakistan included more populated cities such as Karachi, Lahore, Peshawar, Quetta and Rawalpindi/Islamabad. All the them treat very inflexible and some of them give freedom to their children and behave in very flexible manners. This study was aimed to found effects of different parenting styles on adolescent's suicidal ideation.

health professions to know the real hazard from suicidal thoughts.

The current study allows the researchers to highlight the important connection between the parenting style and suicidal ideation. At the family level, the significance of the the parenting styles can not be understated.

A portion of the young people exhibited conflicting reactions in response to different parenting styles. The parenting effects yield creating harmful effects even suicidal ideation. The parenting styles through adolescence is of utmost importance. It would likewise be significant to lead interviews with the parental figures to continue to an investigation of tests that are increasingly illustrative of the all-inclusive community.

authoritative/flexible father parenting style is significantly negatively correlated with suicidal ideation. Results showed that parenting styles are significantly having impact on adolescent's suicidal ideation.

The study will help educational institutes to improve parents teaching meeting and discuss parental issues and their impact on student mental health and possible worst results high level suicidal ideation.

instruments used in the study were self-report measures. In future, other measures besides the self-report measures could be used to increase the credibility of the results. Future research may collect large sample. In future researches, age range should be from 13 to 25 years. 


\section{CONFLICT OF INTEREST}

The authors declare no conflict of interest.

\section{SOURCE OF FUNDING}

The authors declare no funding.

\section{REFERENCES}

Arria, A. M., O'Grady, K. E., Caldeira, K. M., Vincent, K. B., Wilcox, H. C., \& Wish, E. D. (2009). Suicide ideation among college students: a multivariate analysis. Archives of suicide research : official journal of the International Academy for Suicide Research, 13(3), 230-246. doi:10.1080/13811110903044351

Baumrind, D. (1991). Parenting styles and adolescent development. In J. BrooksGunn, R. M. Lerner, \& A. C. Petersen (Eds.), The encyclopedia on adolescence (pp. 746-758). New York: Garland Publishing.

Beck, A. T., Kovacs, M., \& Weissman, A. (1979). Assessment of suicidal intention: The Scale for Suicide Ideation. Journal of Consulting and Clinical Psychology, 47(2), 343-352. doi: 10.1037/h0061997

Bibi, F., Chaudhry, A. G., Awan, E. A., \& Tariq, B. (2013). Contribution of parenting style in life domain of children. IOSR Journal of humanities and social science (IOSR-JHSS), 12(2), 91-95.

Buri, J.R. (1991). Parental Authority Questionnaire. Journal of Personality and Social Assessment, 57, 110-119. doi: 10.1080/17405629.2015.1047338

Cole, M., Cole, S. R., \& Lightfoot, C. (2005). The development of children. Macmillan.

Darling, N., \& Steinberg, L. (1993). Parenting Style as Context: An Integrative Model. Psychological Bulletin. 113, 487-496. doi: 10.1037/0033-2909.113.3.487.

Darling, N. (1999). Parenting Style and Its Correlates. Epidemiology of suicide in Asia, Suicide and Suicide Prevention in
Asia, 2008 Geneva, Switzerland World Health Organization (pg. 7-18).

Hendin, H., Phillips, M. R., Vijayuakumar, L., Pirkis, J., Wang, H., Yip, P., Wasserman, D., Bertolote, J. M., \& Fleischmann, A. (2008). Suicide and Suicide Prevention in Asia. World Health Organization.

Hoyert, D. L., Heron, M. P., Murphy, S. L., Kung, H. C. (2006). Deaths: Final data for 2003. National vital statistics reports; vol 54 no 13. Hyattsville, MD: National Center for Health Statistics. Available

from:http://www.cdc.gov/nchs/data/nvsr/ nvsr54/nvsr54_13.pdf. 2006.

Kann, L., Kinchen, S., Shanklin, S. L., Flint, K. H., Kawkins, J., Harris, W. A., Lowry, R., Olsen, E. O., McManus, T., Chyen, D., Whittle, L., Taylor, E., Demissie, Z., Brener, N., Thornton, J., Moore, J., Zaza, S. (2014). Centers for Disease Control and Prevention: Youth risk behavior surveillance - United States, 2013. $M M W R$ Surveillance Summary, 63Suppl, 4,1-168.

Khokher, S., \& Khan, M. (2005). Suicidal Ideation in Pakistani College Students. Crisis. 26. 125-7. doi: 10.1027/02275910.26.3.125.

Kochanek, K. D., Murphy, S. L., Anderson, R. N., \& Scott, C. (2004). Deaths: Final data for 2002. National vital statistics reports; vol 53 no 5. Hyattsville, MD: National Center for Health Statistics.

Lai, K., \& McBride-Chang, C. (2001). Suicidal ideation, parenting style, and family climate among Hong Kong adolescents. International Journal of Psychology, 36, 
81-87. doi: 10.1080/00207590042000065.

Logan, J. E., Crosby, A. E., \& Hamburger, M.

E. (2011). Suicidal ideation, friendships with delinquents, social and parental connectedness, and differential associations by sex: Findings among high-risk pre/early adolescent population. Crisis: The Journal of Crisis Intervention and Suicide Prevention, 32(6), 299-

309. https://doi.org/10.1027/02275910/a000091

Lubell, K. M., Kegler, S. R., Crosby, A. E., \& Karch, D. (2007). Suicide Trends Among Youths and Young Adults Aged 10--24 Years - United States, 19902004. Division of Violence Prevention, National Center for Injury Prevention and Control, CDC, 56(35), 905-908.
Nunes, F., \& Mota, C. P. (2016). Parenting Styles and Suicidal Ideation in Adolescents: Mediating Effect of Attachment. Journal of Child and Family Studies, 26, doi: 10.1007/s10826-016-0611-6.

Reynolds, W. M. (1988). Suicidal Ideation Questionnaire: Professional manual. Odessa, FL: Psychological Assessment Resources.

Simon, R. I. (2008). Behavioral risk assessment of the guarded suicidal patient. Suicide Life Threat Behavior, 38(5), 517-522.

Tse, W.L., \& Bagley, C. (2002). Suicidal behavior, bereavement and death education in Chinese adolescents. Ashgate Publishing, VT.

Veenes, J.E. (1973). The social meaning of parenthood, Psychiatry Journal for the Study of Interpersonal Process, 36, 291 310. 